\title{
The Development of the Volumetric and Spatial Structure of Residential Areas in a Large City: The Experience of Krasnoyarsk, Russia
}

\author{
Alexey Lipovka ${ }^{1, a}$ Irina Fedchenko, ${ }^{1, *}$ \\ ${ }^{1}$ Institute of Architecture and Design, Siberian Federal University, Krasnoyarsk, Russia \\ aEmail: alex.lipovka@gmail.com \\ *Corresponding author. Email: ifedchenk@inbox.ru
}

\begin{abstract}
The study analyses the transformation of the material-spatial environment of the residential areas of Krasnoyarsk. On the basis of geoinformation analysis of open data on residential development, the regularities of the formation of periods in the development of housing construction are generalized. An assessment is given, which reveals the correlations between calculated indicators of residential planning units such as area, building density, total housing stock, number and density of the population, and periods of their development. Based on a comparative metric analysis of the most characteristic morphotypes of residential planning units, a conclusion is made about the regularity of the construction of their structure. The dynamics and nature of the data revealed made it possible to formulate the main trends in the transformation of residential areas: changes in the spaceplanning characteristics of buildings; expansion of representative offices of types of residential buildings, unforeseen point construction of new objects in the residential environment; development of private and public relations in residential areas; in general, changes in the characteristics of the density and intensity of development in the post-Soviet period.
\end{abstract}

Keywords: Urban planning, Urban morphology, Residential planning units.

\section{INTRODUCTION}

In the early XXI century, many major Russian cities are transformed in terms of both content and planning structure. The upward dynamics of housing construction, densification of buildings, dissonance of the architectural environment lead to morphological transformations in cities. Changes in social, economic and functional processes in large cities lead to reshaping of residential areas. These processes result in the expansion of representative types of residential development and public open spaces, the unforeseen infill development of new objects in the living environment. In general, there is a consistent change in volumetric and spatial characteristics of development. The process of modern urban planning is connected with the

*Fund: The study was carried out with the financial support of the Krasnoyarsk Regional Science Foundation within the framework of the scientific project "Tendentsiy razvitiya planirovochnoy struktury Kransonyarska". necessity of taking into account objective realities and laws of development of urbanized territories.

The new laws on the comprehensive development of territories in the Russian Federation are being adopted. ${ }^{1}$ Within their framework it is planned to determine the planning elements of residential areas for urban redevelopment. All of these processes form the rationale behind the study of the main stages of the evolving spatial development in the post-Soviet urbanized territories and the analysis of contemporary patterns of development of residential areas in the early XXI century. The basis of the modern formation of residential are as in Russian cities is the development of mass housing and renovation of the existing housing stock. In light of this, it becomes

1. December 30, 2020 Federal law № 494-FZ "On amendments to the Urban Planning Code of the Russian Federation and individual legislative acts of the Russian Federation for ensuring the integrated development of territories" was adopted. 
especially relevant to study current transformations in the existing microdistricts, understand the trends of housing development, changes in the physical shape and architectural character of the largest Russian cities, and define the new morphotypes of residential development.

\section{METHODOLOGY}

The aim of the present study is to determine the patterns of development of the volumetric and spatial structure of residential areas in different formation periods on the basis of GIS analysis of data from open statistical sources of Krasnoyarsk city.

The following research objectives are defined:

- To study approaches to the periodization of mass housing construction in Russia, established in the theory of urban planning and to determine the morphological periods of residential development in Krasnoyarsk;

- To study the practices of GIS analysis practice and conduct comprehensive calculation of Krasnoyarsk housing development indicators (exploratory data analysis) on the basis of open data;

- To identify and compare characteristic morphotypes of residential planning units in Krasnoyarsk using key volumetric and spatial indices.

Theoretical basis of the study is formed by the works devoted to the study of spatial and morphological development of cities, and to defining development periods. The theory of urban development witnesses the emergence of research on the definition of the main periods of urban transformation and dynamics of housing construction. The first period of mass housing construction in the theoretical studies is associated with the process of industrialization in housing construction sphere and the formation of residential microdistricts. Thus, by the end of the 1950 s, the practice of urban planning witnessed the emergence of microdistrict as an "algorithm" for the design of residential areas based on the calculation of development density, accessibility radiuses of service facilities, and developing nomenclature of typical elements.

Experts recognize the second stage as an increase in the density of buildings resulting from the higher number of stories, beginning in the late 1960s. Kosenkova defines a stage in the development of late Soviet urban planning (1970-
1980) as the formation of a new spatial paradigm of "humanization of the architectural environment" in the formation of territories for mass residential development [1]. Ptichnikova defines two states of the spatial-planning structure of cities: the last decades of the XX century and the beginning of the XXI century. ${ }^{2}$ Portnov notes that the transition of a city to a market economy can be characterized as critical. He identifies the following factors of the transition state: the transfer of land and real estate into private ownership, privatization of service sector, the introduction of differentiated cost indicators of land use, the collapse of the state building industry, the emergence of small, private construction firms [3]. Kukina defines the main regularities of the morphological transformation and development of the territories in a post-socialist city [4]. Several works have studied the main trends in the transformation of the concept of microdistrict in the post-Soviet space [5], [6], [7].

The practical basis of this study is a method of geoinformation analysis of spatial data of cities exploratory data analysis. ${ }^{3}$ This is an analysis of the basic features of the objects under study. As applied to this study, it is the calculation of residential development parameters, finding common patterns, distributions and anomalies, visualized through histograms and mapping. The works of Vítor Oliveira analyze the formation of an interdisciplinary scientific subject - urban morphology - at the nexus of engineering, technical sciences and architecture [8]. In his works the author explains the analytic principles of a city's physical form, how different agents change this form over time and how different processes are involved in this transformation [9]. The Mathematics of Urban Morphology, under the general direction of Luca D'Acci, brings together applied research based on the conjunction of universal laws and phenomenological description of processes. The work considers case studies of multidimensional analysis of urban areas with the help of statistical physics and mathematical calculations [10]. Mapping Urbanities Morphologies defines the methods of spatial data visualization [11]. In the work "Moskva: Kurs na Poltsentrichnost"', based on the Morpho

2. Based on a comparative analysis of the spatial structure transformation in 15 major post-soviet Russian cities.

3. The concept was introduced by mathematician John Tukey, who formulated the goals of such analysis as follows: maximum "penetration" into data, identifying the main structures, choosing the most important variables, detecting outliers and anomalies, testing the main hypotheses, developing initial models. 
methodology, the research team studied the impact of physical urban form in Moscow on the viability of planning units in relation to the set of parameters of the spatial syntax [12], [13]. Special attention should be paid to the works devoted to the GIS analysis of the dynamic morphological development in residential planning units [14], [15], [16], [17].

To date, there has been a lack of comprehensive research into development patterns of volumetric and spatial structure of residential areas in Krasnoyarsk through methods of mathematical modeling and GIS analysis, which determines the relevance of this work.

\section{IDENTIFICATION OF MORPHOLOGICAL PERIODS IN KRASNOYARSK RESIDENTIAL AREAS}

The first period of mass housing construction in Krasnoyarsk correlates with the model residential 5-storey development near large industrial enterprises in 1960-1980. By the end of the 1960s, the microdistrict features multi-story buildings of 916 floors because of the desire to use the urban area more efficiently. In 1971-1972 the factory "Kultbytstroy" (the original name of the enterprise Factory ZhBI-2) started building series 111-97 for the construction of residential buildings, forming a then-new principle of "free" microdistrict layout with increased number of floors. There emerged a tendency to change the overall planning structure of the city from a relatively compact form to discrete one, with a system of self-sufficient industrial and residential formations [18]. At the beginning of the XXI century there is a fairly active, very rapid and almost uncontrolled growth of new development, which is accompanied by simultaneous problems of aggressive environment, high density and traffic load [19].

The analysis of open data from the "Reforma ZhKKh" portal allowed obtaining the initial data for the calculation of residential development parameters. ${ }^{4}$ In total, as of 01.03.2021 the database contains 5957 records of Krasnoyarsk residential apartment buildings. The geodatabase collected in this research includes generalized information on residential and non-residential buildings of the city, which contains the number of residents, residential

4. Government Corporation of the Russian Federation Fund of Assistance to the Reform of the Housing and Utilities Sector https://www.reformagkh.ru/ area and built-up area, based on which the calculations were made. The calculation was carried out in the QGIS geographic information system on the basis of residential building geometry, obtained from the open source OpenStreetMap. ${ }^{5}$

"Figure 1" features Krasnoyarsk housing development in 1960-2020 in the form of accumulative histogram where the abscissa axis is the year of construction, and the ordinate axis - the total area of homes. This histogram allows concluding that there is a correlation between the volume and historical periods of residential development. One can distinguish characteristic "waves" of the residential development, which have pronounced rising and falling fronts.

Thus, the growing pace residential construction, which is put into service, allows defining three hypothetical time periods at the turn of the century:

- I period - Formation of 5-story housing stock by standard series (1960-1980)

- II period - Development of empty territories with 9-story panel housing (1980-2000)

- III period - Modern processes of housing construction (2000-2020)

After identifying the periods of mass housing construction in Krasnoyarsk, the present research defined residential planning units (189 units) using predominant construction date of houses in their boundaries, street and road network and building morphology ("Figure 2"). Further, the calculation and exploratory analysis of these planning units was carried out. The analysis shows significant transformation of residential areas over time.

\footnotetext{
5. Open Spatial Data Portal https://www.openstreetmap.org/
} 


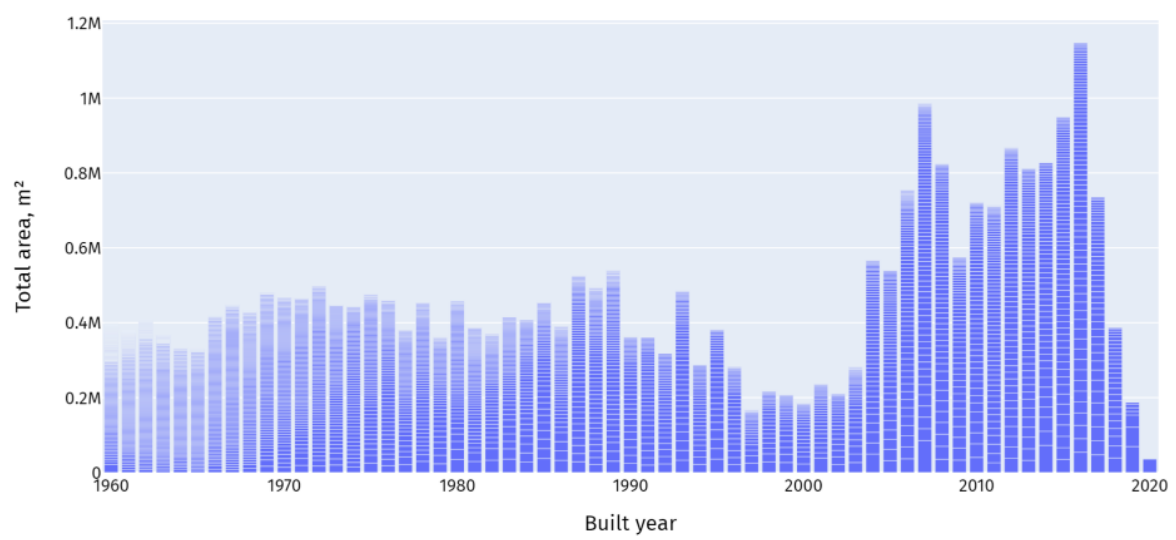

Figure 1 Histogram of Krasnoyarsk development characteristics 1960-2020.

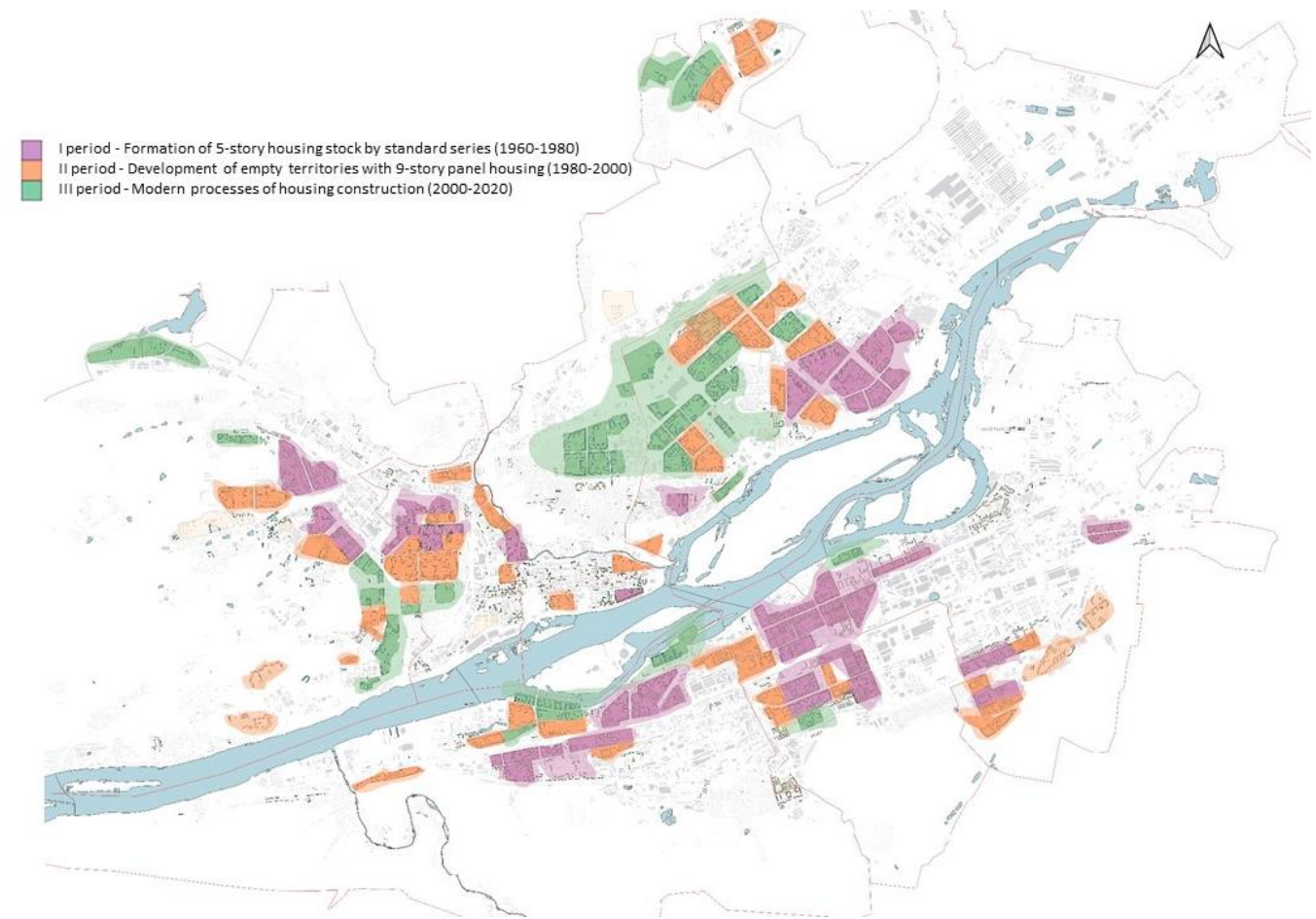

Figure 2 Morphological periods of residential planning units in Krasnoyarsk.

\section{COMPREHENSIVE ANALYSIS OF VOLUME AND SPATIAL STRUCTURE OF RESIDENTIAL PLANNING UNITS OF KRASNOYARSK}

\subsection{Calculation and Visualization of Residential Area Parameters}

At the first stage, research featured the calculation of basic characteristics of residential planning units (microdistricts). For that purpose, the following data list was gathered and prepared in
QGIS software: polygonal layer of buildings; polygonal layer of planning units; polygonal layer of school territories, kindergartens, etc.; table of data on housing stock from the "Reforma ZhKKh" portal. All data stored in the GeoPackage format are up-to-date. The following calculations were made and the map-schemes of the results drawn:

- with respect to the area of residential development, the largest median value correlates with the first period of mass housing construction. This means that the modern-day Krasnoyarsk city is dominated by 5-story buildings mostly of standard 
series, in terms of the square area and number of buildings;

- by the total area of all residential space there dominate residential buildings built in the third, modern, development period, which is also confirmed by the dynamic growth of square meterage of residential space commissioned in Krasnoyarsk;

- the highest population density correlates with the modern period of housing construction, and its median value is 450 people/ha, while the maximum value is 1000 people/ha. The lowest population density according to the median value correlates with the first period of housing development and is 270 people/ha;

- in terms of the development coefficient, the first period of development prevails, with a median value of 0.17 ;

- in terms of residential development intensity coefficient third period greatly exceeds the rest by median values with 1,2 , while the first period is 0,7 and second is 0,8 ;

- $\quad$ as for the average number of stories, there is a sharp growth in the third period (median number of stories is 10), with median values of 4 stories for the first period and 6 for the second one.

The results are visually presented on "Figure 3".

The results of the analysis of the residential and non-residential use of space and the average floor area of the apartments are found to be interesting. Thus, there is a gradual increase in the proportion of non-residential space in residential buildings built between 2000 and 2020, which indicates the growth of public and business activity on the first floors, the emergence of fire stairs and communal areas in the stairwells.

After determining the basic parameters of volume and spatial structure of residential areas, the study proceeded to comparative analysis of change patterns of those parameters.

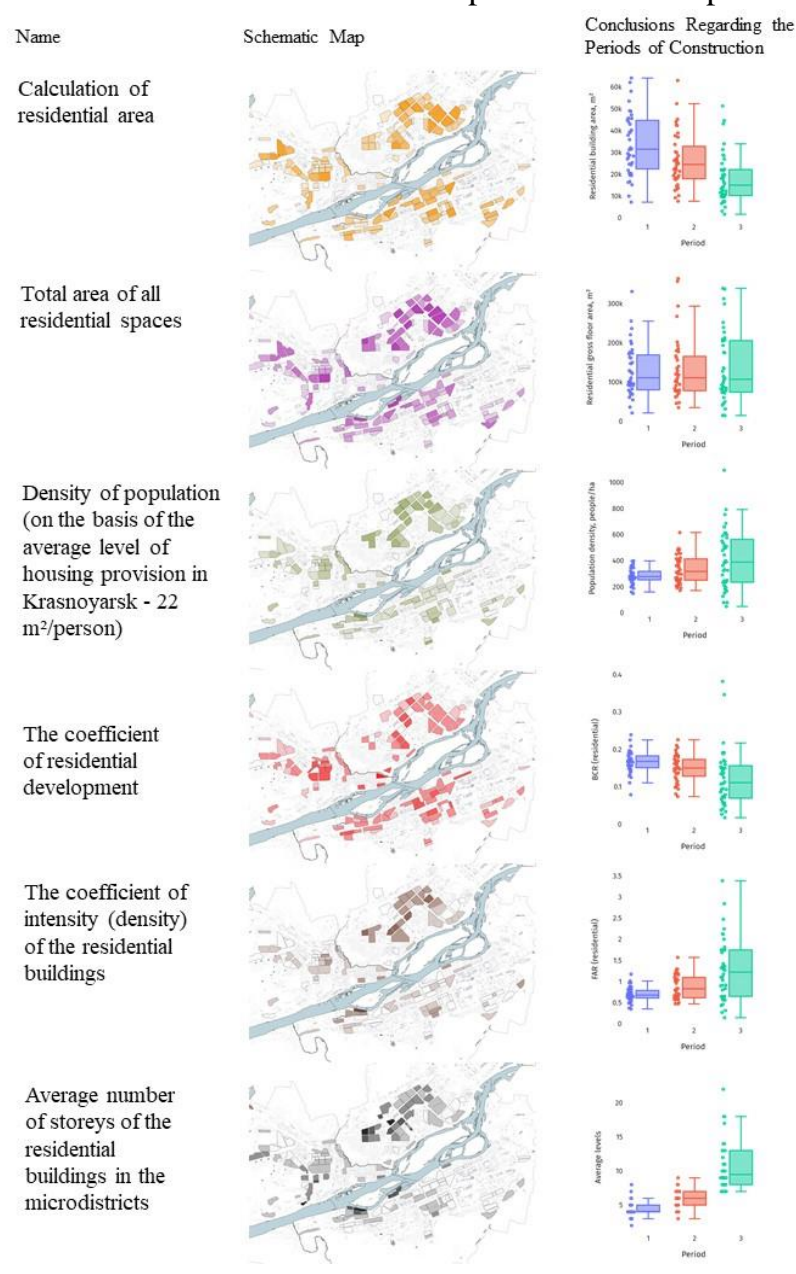

Figure 3 Analysis of estimated parameters of Krasnoyarsk city planning units in relation to the periods of their construction. 


\subsection{Exploratory Analysis of the Correlation Between the Calculated Parameters of Residential Areas}

The aim of such analysis is to visualize the dependence of changes of the volume and spatial form of Krasnoyarsk residential areas based on the correlation of individual parameters.
The study was carried out using specialized libraries of programming language Python, designed for the processing and visualization of data, which enabled a visual presentation of the dependency matrix for the parameters of residential development ("Figure 4").

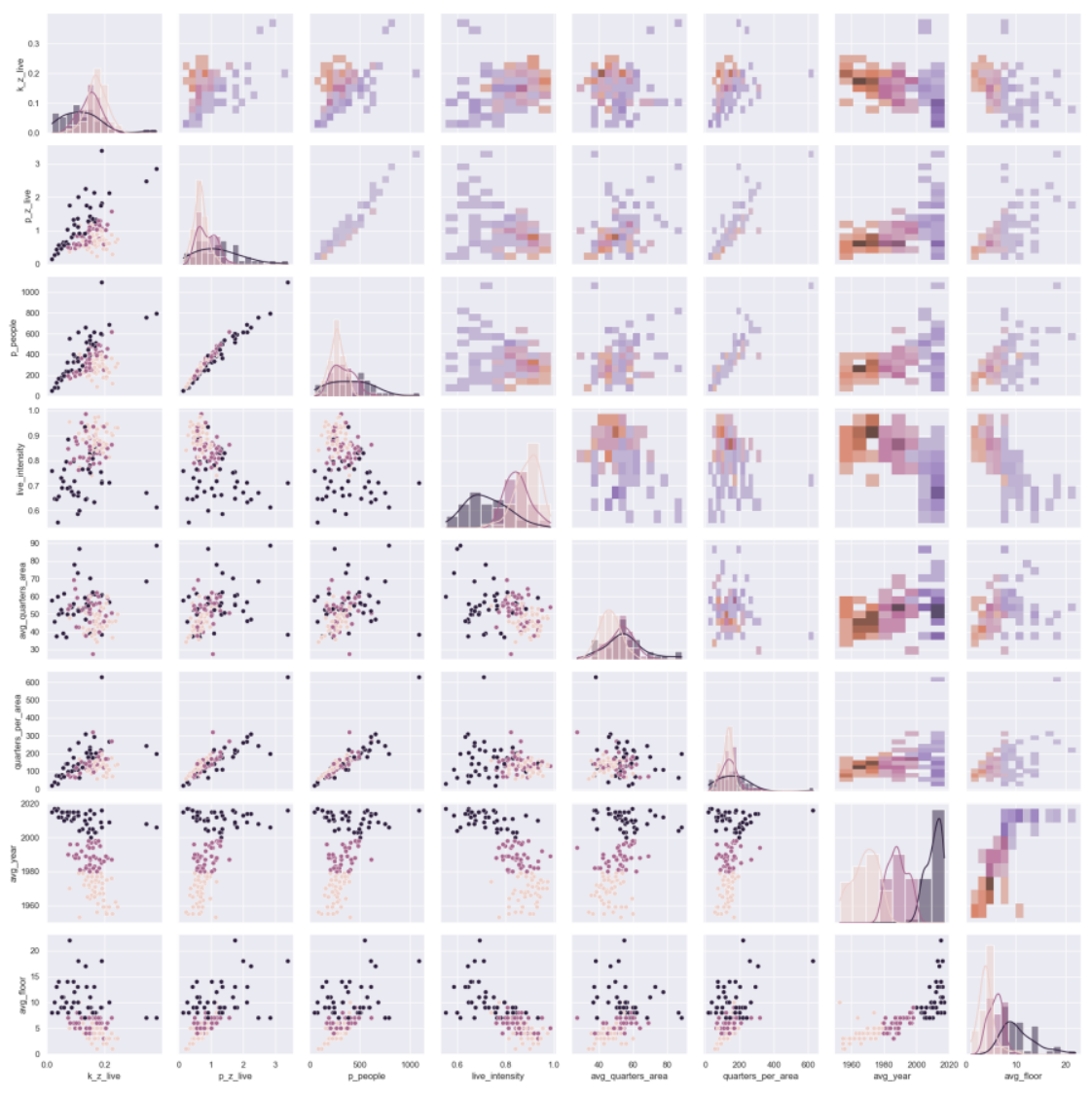

Figure 4 Dependency matrix of Krasnoyarsk residential development parameters.

This research features a sample of parameters taken to establish the patterns based on the correlations of which it became possible to formulate the following assumptions:

- The volume of total residential area increases while the development footprint remains the same. This becomes evident when comparing the growth rate of total residential area over time and the built-up area of the commissioned residential houses;

- There is an increase in the density of residential development with a decrease in the development coefficient due to increasing number of stories. This is evidenced by comparing the coefficient of residential development, the coefficient of intensity (density) of residential development and the average number of stories of houses in microdistricts;

- Population density increases in proportion to the increase in the number of stories and the coefficient of intensity (density) of residential development. This result is achieved by comparing the population density, the coefficient of intensity (density) of residential development and the average number of stories of residential buildings in the microdistricts;

- The average area of apartments is growing, while the number of apartments is growing moderately. This is seen through comparing the data on the number and area of apartments; 
- The share of non-residential space in the residential building is growing, while the total area of residential buildings is also increasing. This is evidenced by comparing the intensity (density) of residential space use and total residential area.

- The share of residential premises in a residential house decreases which is observed when comparing the total residential and non-residential areas of the houses;

- The variety of archetypes of residential development increases which is seen when comparing the data on the standard series and individual projects of residential buildings.

Comprehensive study into the dynamic changes of volume and spatial characteristics of residential development allows us to identify the trends toward an increase in the intensity of residential development and an increase in population density.

\section{COMPARATIVE ANALYSIS OF CHARACTERISTIC MORPHOTYPES OF RESIDENTIAL PLANNING UNITS}

The identified general trends and most significant changes in the evolution of the spatial structure of residential planning units for sixty years period from 1960s till 2020 allows to make
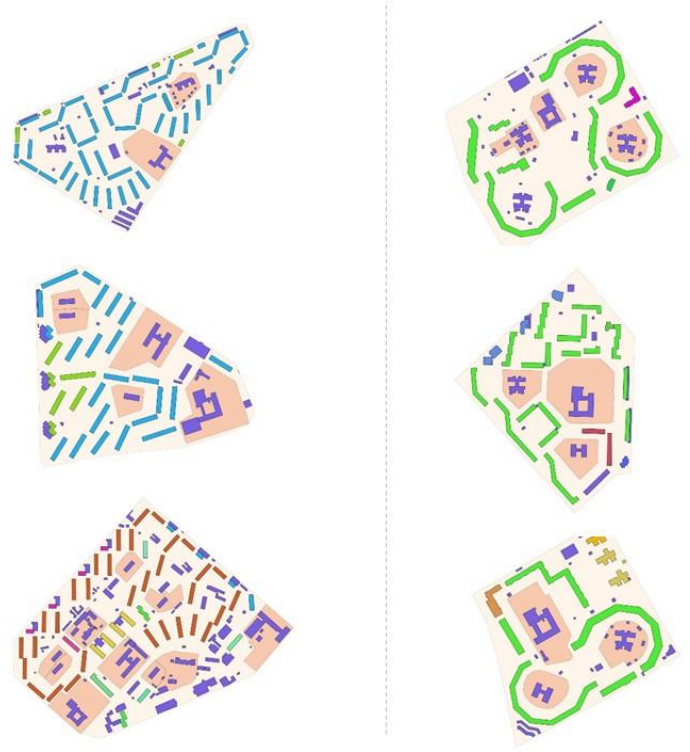

conclusions on the change of the morphological structure of Krasnoyarsk microdistricts. The study identified and analyzed characteristic morphotypes of residential development, inherent in each period ("Figure 5"):

- Morphotype "Linear Development" characteristic of period I (1960-1980): the largest number of buildings and the development footprint of mainly linear development with median of 4 stories; population - 4763 people; population density - 219 people/ha. This morphotype is characteristic of the least integration of public and business functions in residential buildings.

- Morphotype "Free Development" typical for the II period (1980-2000): free planning buildings with the median of 7 stories; population - 6,370 people; population density - 316 people/ha. It is characterized by a shift from discrete forms to higher densities.

- Morphotype "Mixed Development" characteristic of III period (2000-2020): the mixed type of buildings with a median of 10 stories; population - 9658 people; population density - 589 persons / ha. This morphotype features the highest rates of integration of non-residential spaces into residential buildings, along with a high diversity of architectural types among residential buildings.

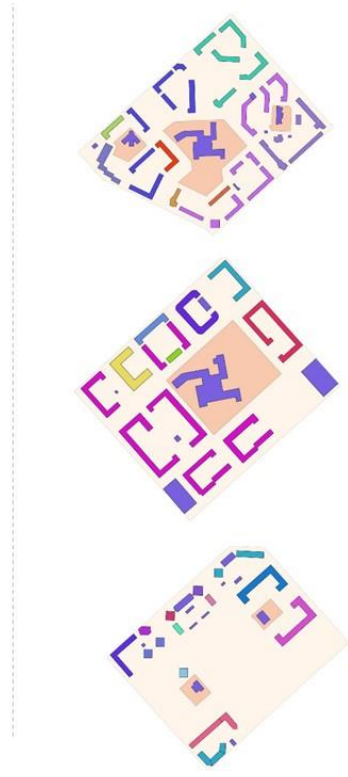

Figure 5 Morphotypes of Krasnoyarsk city residential planning units: a) Morphotype "Linear development" characteristic of I period (1960-1980); morphotype "Free development", characteristic of II period (1980-2000); morphotype "Mixed Development" characteristic of III period (2000-2020). 
The comparison of median parameters by the periods of residential development in Krasnoyarsk is shown in "Table 1".

Table 1. Comparison of median values of parameters by periods of Krasnoyarsk residential development

\begin{tabular}{|c|c|c|c|}
\hline & I Period & $\begin{array}{l}\text { II } \\
\text { Period }\end{array}$ & $\begin{array}{l}\text { III } \\
\text { Period }\end{array}$ \\
\hline The coefficient & 0,7 & 0,8 & 1,2 \\
\hline Development & 0,17 & 0,15 & 0,11 \\
\hline Population & 270 & 320 & 400 \\
\hline Average & 4 & 6 & 10 \\
\hline Residential .. & 0,9 & 0,85 & 0,7 \\
\hline $\begin{array}{l}\text { Intensity } \\
\text { coefficient of } \\
\text { nonresidential }\end{array}$ & 0,05 & 0,08 & 0,09 \\
\hline $\begin{array}{l}\text { Typological } \\
\text { diversity } \\
\text { architecture }\end{array}$ & Low & Low & High \\
\hline
\end{tabular}

\section{CONCLUSION}

The research has defined characteristic morphological periods of the mass residential development in Krasnoyarsk: 1960-1980- first period, associated with the industrialization of development; 1980-2000- second wave of housing development, associated with an increase in the number of stories and the introduction of new series of panel residential buildings; 2000-2020 - the modern period characterized by an increase in residential development density. Based on comprehensive analysis of the parameters of Krasnoyarsk residential development using open data the research presented critical values for the periods of construction. The exploratory analysis of the correlation between the parameters of residential areas established the patterns of development over time. The comparative analysis of characteristic morphotypes of residential planning units of Krasnoyarsk using the key volume and spatial parameters allowed defining trends of morphological transformations: the departure from the discrete forms to the dense high storied development.

At the present stage of the development of urban planning in Russia, there is an acute issue of densification of development in large cities, while maintaining comfort and a favorable microclimate. At the beginning of the 21 st century it is impossible to carry out any urban planning research, without considering such basic characteristics as space, dynamics of territorial growth and population. Monitoring of development of the city territories in general and with the use of big data analysis, can set the nature and scenario of the future development of territories. GIS analytic technologies should play an important role in urban planning, as they have significant potential to bridge the gap between the conceptual understanding of cities and real urban data collected by various means [20]. It becomes paramount at any level to determine the strategic guidelines for the development of a post-industrial city and the role of planning structure elements.

\section{AUTHORS' CONTRIBUTIONS}

Fedchenko I. G. defined and delineated borders of residential planning units in Krasnoyarsk, defined morphological periods, constructed databased maps, carried out a literature review; Lipovka A. Yu. aggregated and joined open data, determined methodology behind calculation of residential planning units indicators, made exploratory data analysis, constructed box plots and histograms.

\section{REFERENCES}

[1] Kosenkova YU.L. New scientific approaches to the study of the architectural and urban planning heritage of the Soviet period (Novye nauchnye podhody $\mathrm{k}$ izucheniyu arhitekturnogradostroitel'nogo naslediya sovetskogo perioda) in: Balandinskie chteniya. T. XIII, 2018, pp. 339-342 [in Russian]

[2] Ptichnikova G.A., Transformations of the spatial structure of the largest cities of Russia in the post-Soviet period (Transformations of the spatial structure of the largest cities of Russia in the post-Soviet period) in: Biosphere compatibility: people, region, technology, 2020, no. 1. C.42-56. DOI: 10.21869/23111518-2020-29-1-42-56) [in Russian]

[3] Portnov B.A. Urban planning during the transition to a market economy, Krasnoyarsk. (Urban planning during the transition to a market economy): KISI, 1994. 71 p. [in Russian]

[4] Kukina I.V., Regulations of the "free development" of the urbanized territories in the planned agglomerations in foreign 
countries (Reglamenty «svobodnogo razvitiya» urbanizirovannyh territorij V planiruemom sozdanii aglomeracij v zarubezhnyh stranah), in: Academia. Architecture and Construction, 2011, no. 3, pp. 81-86. [in Russian].

[5] Fedchenko I.G, Planned residential units: New development trajectories in: Youth, Science, Solutions: Ideas and Prospects (YSSIP-2016): Proceedings of the III International Young Researchers Conference "Youth, Science, Solutions: Ideas and Prospects", 2017, vol. 1800. URL: http://elib.sfukras.ru/handle/2311/69593 (accessed: 17.03.2021).

[6] Metspalu P, Daniel B. H, Revisiting the role of architects in planning large-scale housing in the USSR: the birth of socialist residential districts in Tallinn, Estonia, 1957-1979 in: Planning Perspectives, 2017 To link to this article:

http://dx.doi.org/10.1080/02665433.2017.134 8974 (accessed: 17.03.2021).

[7] Monclús J, Medina C.D. Modernist housing estates in European cities of the Western and Eastern Blocs in: Planning Perspectives, 2016, 533-562 pp, To link to this article: https://doi.org/10.1080/02665433.2015.11026 42 (accessed: 17.03.2021).

[8] Oliveira V., Urban Morphology, Springer International Publishing Switzerland., 2016, $192 \mathrm{p}$.

[9] Oliveira V., The study of urban form: Different approaches in: Urban Morphology: An Introduction to Study Physical Form Cities, Cham, Switzerland: Springer, 2016, pp. 87-149.

[10] D'Acci, Luca (Ed.) The Mathematics of Urban Morphology Modeling and Simulation in Science, Engineering and Technology, Springer Nature Switzerland AG, 2019,

[11] Dovey K., Pafka E., Ristic M. Mapping Urbanities: Morphologies, Flows, Possibilities, Routledge, 2018, 290 p

[12] Kotov E., Goncharov R. Connecting Morpho to urban vitality: the case of Moscow, in: Book of Abstracts. 25th ISUF International Conference: Urban Form and Social Context: from traditions to newest demands. Krasnoyarsk, 2018. 164-164 pp

[13] Ezquerra I., Díez-Medina C., Monclús J Zaragoza: Two Housing Estates, Two Neighbourhoods. Comparative Cartographic Analysis of Two Urban Growth Forms. In: Graphical Heritage. EGA 2020. Springer Series in Design and Innovation, vol 7. Springer, Cham. https://doi.org/10.1007/9783-030-47987-9_20

[14] Sergio G-P, Oliveira, V, Monclus, J, Díez M.C. A methodological approach for a diagnosis on the quality of open spaces in mass housing estates, in: Cities. 103 p.

[15] Qu B., Leng J., Ma J., Investigating the Intensive Redevelopment of Urban Central Blocks Using Data Envelopment Analysis and Deep Learning: A Case Study of Nanjing, China, in IEEE Access, vol. 7, pp. 109884109898, 2019, doi: 10.1109/ACCESS.2019.2933691

[16] Yu Ye, Dong Li , Xingjian Liu, How block density and typology affect urban vitality: an exploratory analysis in Shenzhen, China, Urban Geography, 2018, 631-652 pp, DOI: $10.1080 / 02723638.2017 .1381536$

[17] Pinho P, Oliveira V. Cartographic Analysis in Urban Morphology. Environment and Planning B: Planning and Design. 2009;36(1) , 107-127. doi:10.1068/b34035

[18] Gorbachev V.T., Kradin N.N., Kradin N.P., Krushlinskij V.I., Stepanskaya T.M. Urban planning of Siberia (Gradostroitel'stvo Sibiri); SPb.: Kolo, 2011, 784.p. [in Russian]

[19] Kukina I.V, Fedchenko I.G. Morphological Development of the Microdistricts under the Pressure of the Post-socialist Transformations: Case Studies of Siberian Cities, in: Proceedings of the «International Conference on Cities and Change: Three Decades of Postsocialist Transition 1989-2019»; Scientific Editors: Nebojša Camprag, Anshika Suri. - TU prints, TU Darmstadt, Germany, 2019, pp.137-147

[20] Lipovka A.Yu. GIS technology of unification (GIS-tekhnologii edineniya), in: A city fit for life: materials of the first International scientific and practical conference "Modern problems of architecture, urban planning, design", Krasnoyarsk: Sib.FU, 2014, 80-82 pp. [in Russian] 